\title{
Comparative Cephalometric Analussis of Angle Class II Division 1 Malocclusion Between Nepalese and Chinese Subjects
}

\author{
Dr Bishnu Prasad Sharma,' Dr Chang Xin² \\ 'Patan Academy of Health Sciences, Department of Dentistry, Lalitpur, Nepal \\ 2Dalian Medical University, Dalian, China
}

Correspondence: Dr Bishnu Sharma; email: bishnunl@yahoo.com

\section{ABSTRACT}

Objective: To identify the craniofacial features of Nepalese and Chinese subjects with Angle Class II division 1 malocclusion; and to compare between Nepalese and Chinese samples and Nepalese gender groups.

Materials \& Method: The cephalometric radiographs were obtained from 96 Nepalese (mean ages $16.34 \pm 5.4$ years) and 39 Chinese (mean age 17.18 \pm 7.1 years) subjects with Angle Cass II division 1 malocclusion. Ten skeletal, nine dental and three soft tissue variables were investigated.

Result: The craniofacial features between Nepalese and Chinese samples showed significant differences among fifteen of the twenty-two variables studied; whereas in comparison between gender groups, six parameters were significantly different.

Conclusion: Both samples showed well positioned maxilla, retrusive mandible and Class II skeletal tendency. In comparison, maxilla was more protrusive, mandible was more retrusive and overjet was more increased in Chinese. The Nepalese showed more prominent nose and chin.

Key words: Angle Class II division 1 malocclusion, cephalometry, ethnic variation

\section{INTRODUCTION}

Angle defined Class II division 1 malocclusion as characterized by a distal relation of the lower teeth to the upper to the extent of more than one-half the width of one cusp and the maxillary incisors being protrusive.' Class II division 1 malocclusion, most of the times is caused by a retrognathic mandible. ${ }^{2-5}$ Retrognathic mandible, maxillary prognathism and reduced vertical skeletal jaw relationship are the most common characteristics of Class II division 1 malocclusion. ${ }^{5}$ Majority of researchers, however, conclude that the mandible is retrognathic in relation to other cranial structures. $1,2,6,12-14$ The ethnic aspect is an important characteristic in the morphologic variation of malocclusions.?

The purpose of the present study was to identify the craniofacial features in a sample of Nepalese and Chinese subjects with Class II division 1 malocclusion; and to compare between Nepalese and Chinese samples and Nepalese gender groups.

\section{MATERIALS AND METHOD}

The present study was performed utilizing standardized lateral cephalometric radiographs of total 135 subjects comprising of 96 Nepalese samples (42 males, 54 females) collected from Department of Orthodontics, B.P. Koirala Institute of Health Sciences, Dharan, Nepal and 39 Chinese samples (12 males, 27 females) collected from Department of Orthodontics, Dalian Medical University, Dalian, China. Written consent was obtained from all participants after explaining the nature and purpose of the radiograph.

The criteria for inclusion of the sample were natural-born ethnic Nepalese and Chinese, Angle Class II division 1 malocclusion, no craniofacial deformities, no previous orthodontic treatment, maxillofacial surgery or plastic surgery.

Tracing of the lateral cephalometric radiographs was performed with standard manual technique using sharp $3 \mathrm{H}$ pencil. All radiographs were traced and digitized by the principal author to minimize the error. The measurements 
were obtained for ten skeletal, nine dental and three soft tissue parameters. The related landmarks and measurements are shown in Figure 1- 4. All statistical calculations were performed using Microsoft Office Excel 2003 and SPSS version 17.0 software program. Descriptive statistics and independent student t-test were carried out on the data for comparison between Nepalese and Chinese samples and between the genders. Results were considered to be statistically significant when $p \leq 0.05$.

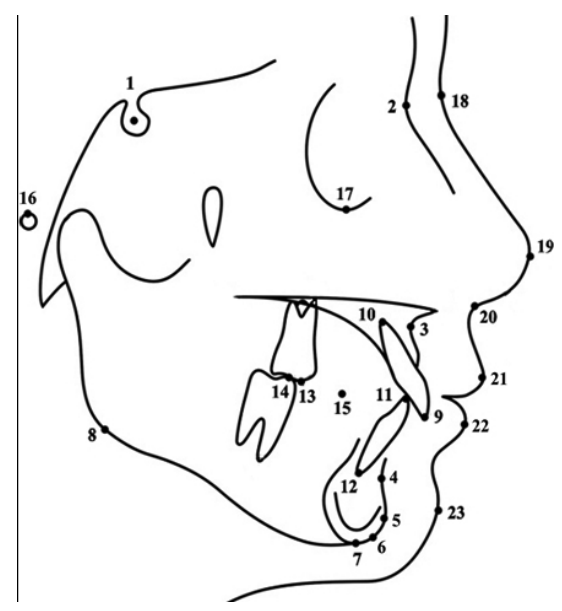

Figure 1: Hard tissue and soft tissue cephalometric landmarks: 1. Sella turcica (S); 2. Nasion (N); 3. Subspinale (A); 4. Supramentale (B); 5. Pogonion (Pg); 6. Gnathion (Gn); 7. Menton (Me); 8. Gonion (Go); 9. Incision superius (Is); 10. Upper incisor apex (UIA); 11. Incision inferius (li); 12. Lower incisor apex (LIA); 16. Porion (Po); 17. Orbitale (Or); 18. Soft tissue nasion (N1); 19. Pronasale (Pr); 20. Subnasale (Sn); 21, Labrale superius (Ls); 22. Labrale inferius (Li); 23. Soft-tissue pogonion (Pgl).

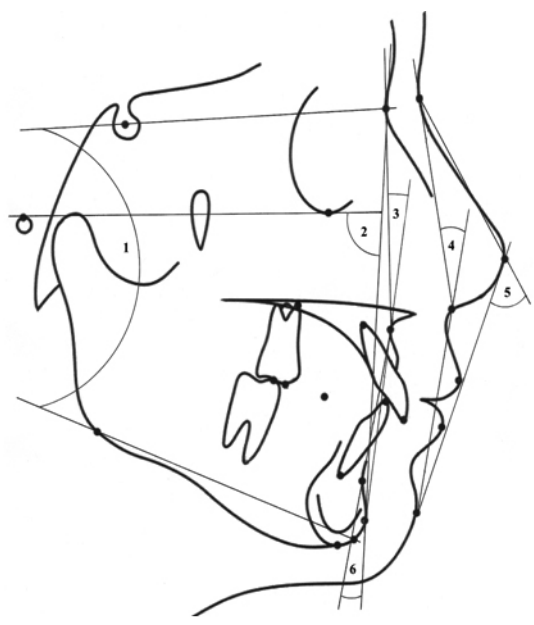

Figure 3: Soft tissue measurements: 1. Mandibular Plane Angle (GoGn to Sn); 2. Facial Angle (NPg-OrPo); 3. Angle of Convexity (NA- APg); 4. Angle of Soft tissue facial convexity (N1-Sn-Pgl); 5. Angle of total Soft tissue facial convexity (N1-Pr-Pg1); 6. A-B Plane Angle (AB-NPg).

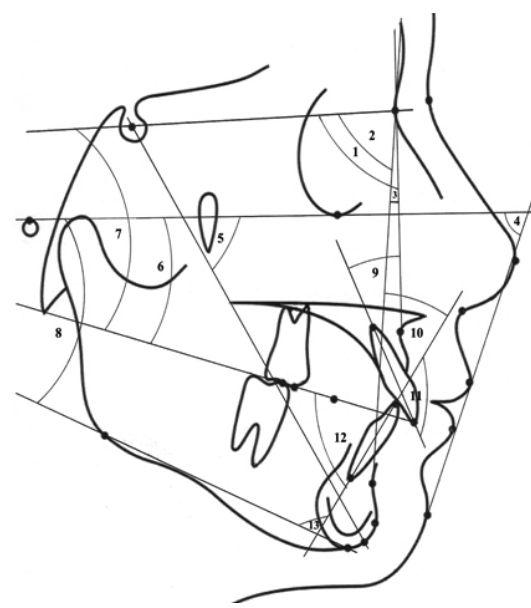

Figure 2: Skeletal measurements: 1. SNA Angle; 2. SNB Angle; 3. ANB Angle; 4. Z Angle; 5. Y-axis (SGn-FH); 6. Cant of occlusal plane (OP-FH); 7. Occlusal Plane Angle (OP-SN); 8. Mandibular Plane Angle (GoMe-FH); 9. U1 to NA Angle; 10. L1 to NB Angle; 11. Inter-incisal (U1 to L1) Angle; 12. L1 to Occlusal Plane (L1-OP) Angle; 13. L1 to Mandibular Plane (L1-GoMe) Angle.

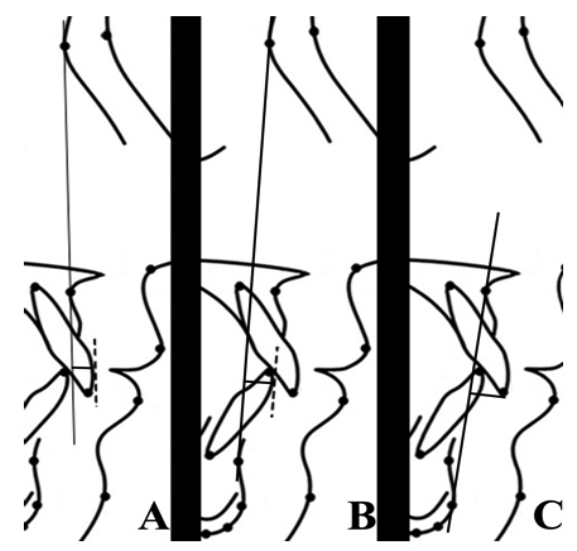

Figure 4: Dental measurements: A. U1-NA Line: The distance between U1 crown and NA line; B. LI-NB Line: The distance between L1 crown and NB line; C. U1-APg Line: The distance between incisal edges of maxillary central incisor to the line from Point A to Pogonion. 


\section{RESULT}

The mean age of the sample was $16.34 \pm 5.4$ years for Nepalese and $17.18 \pm 7.1$ years for Chinese subjects. Comparison of craniofacial features on cephalometric, dental and soft tissue parameters between Nepalese and Chinese sample is presented in Table 1. Craniofacial features and difference between Nepalese male and female subjects is presented in Table 2.

Table 1: Comparison of craniofacial parameters between Nepalese and Chinese subjects with Class II division 1 malocclusion

\begin{tabular}{|c|c|c|c|c|c|c|}
\hline \multirow{2}{*}{ Parameters } & \multicolumn{2}{|c|}{ Nepalese $(\mathrm{N}=96)$} & \multicolumn{2}{|c|}{ Chinese $(\mathrm{N}=39)$} & \multirow{2}{*}{$t$-value } & \multirow{2}{*}{$p$-value } \\
\hline & Mean & SD & Mean & SD & & \\
\hline \multicolumn{7}{|l|}{ Skeletal } \\
\hline Facial Angle & 84.85 & 4.30 & 82.30 & 3.70 & 3.235 & $0.002^{*}$ \\
\hline Angle of Convexity & 6.90 & 7.83 & 12.61 & 5.56 & -4.140 & $0.000^{*}$ \\
\hline A-B Plane Angle & -8.75 & 4.13 & -10.14 & 3.30 & 1.865 & 0.064 \\
\hline MP Angle (GoMe-FH) & 24.94 & 7.86 & 31.73 & 6.97 & -4.688 & $0.000^{*}$ \\
\hline Y-axis & 61.37 & 5.21 & 66.96 & 4.42 & -5.878 & $0.000^{*}$ \\
\hline SNA Angle & 81.22 & 4.30 & 80.88 & 3.25 & 0.450 & 0.653 \\
\hline SNB Angle & 76.52 & 4.00 & 74.71 & 3.29 & 2.489 & $0.014^{*}$ \\
\hline ANB Angle & 4.75 & 2.95 & 6.16 & 2.18 & -2.702 & $0.008^{*}$ \\
\hline MP Angle (GoGn-SN) & 29.13 & 8.21 & 35.88 & 6.65 & -4.559 & $0.000^{*}$ \\
\hline Occlusal Plane Angle & 16.41 & 6.13 & 22.84 & 4.85 & -5.840 & $0.000^{*}$ \\
\hline \multicolumn{7}{|l|}{ Dental } \\
\hline Cant of Occlusal Plane & 9.33 & 5.69 & 15.46 & 4.97 & -5.874 & $0.000^{*}$ \\
\hline Inter-incisal Angle & 112.65 & 10.55 & 116.29 & 11.96 & -1.745 & 0.083 \\
\hline L1 to Occlusal Plane Angle & 65.78 & 7.75 & 66.46 & 8.61 & -0.447 & 0.655 \\
\hline L1 to Mandibular Plane Angle & 98.00 & 8.95 & 96.82 & 7.41 & 0.727 & 0.469 \\
\hline U1-A Pg Line (mm) & 11.39 & 2.78 & 11.10 & 3.04 & 0.540 & 0.590 \\
\hline U1-NA Angle & 35.77 & 9.99 & 26.55 & 8.09 & 5.117 & $0.000^{*}$ \\
\hline U1-NA Linear (mm) & 9.38 & 3.58 & 6.73 & 2.96 & 4.092 & $0.000^{*}$ \\
\hline L1-NB Angle & 27.02 & 7.78 & 30.76 & 7.56 & -2.557 & $0.012^{*}$ \\
\hline L1-NB Linear (mm) & 7.02 & 2.76 & 9.46 & 2.91 & -4.580 & $0.000 *$ \\
\hline \multicolumn{7}{|l|}{ Soft tissue } \\
\hline NI-Sn-Pgl & 21.21 & 6.29 & 20.35 & 5.77 & 0.736 & 0.463 \\
\hline N1-Pr-Pgl & 49.43 & 5.45 & 44.30 & 5.00 & 5.052 & $0.000^{*}$ \\
\hline Z Angle & 66.16 & 7.00 & 63.41 & 6.48 & 2.117 & $0.036^{*}$ \\
\hline
\end{tabular}

* Statistically significant at $p \leq 0.05$

\section{DISCUSSION}

The present study found that, Nepalese subjects possessed slightly higher Sella-Nasion-Point A (SNA) angle than Chinese, however not statistically significant. It suggests well positioned maxilla in relation to cranial base, corroborating to previous studies.2,4,15-17 The sagittal position of the mandible (SNB) was retracted in relation to the cranial base in both samples, which is in agreement with other researchers. ${ }^{1,2,6,8,11-14,20,21}$ Contrarily, Adams in 198122 reported orthognathic position of the mandible. In the present study, mean SNB value was $74.71^{\circ}$ degree for Chinese and $76.52^{\circ}$ for Nepalese; where as another study on Chinese ${ }^{18}$ found SNB value of $77^{\circ}$. The SNB value for Brazilian subjects ${ }^{17}$ was reported as $75.39^{\circ}$. There are relevant data that accept the variations in the position of mandible as inherent characteristic. $2,10,19$

Mean Point A-Nasion-Point B (ANB) angle in Chinese sample was 6.16 $6^{\circ}$ which was $1.4^{\circ}$ greater than the Nepalese. Another study ${ }^{18}$ on Chinese also found similar ANB value of $6^{\circ}$. It indicates that, Chinese have more of Class Il skeletal tendency than the Nepalese. 
Table 2: Comparison of craniofacial parameters between Nepalese male and female subjects with Class II division 1 malocclusion

\begin{tabular}{|c|c|c|c|c|c|c|}
\hline \multirow{2}{*}{ Parameters } & \multicolumn{2}{|c|}{ Male $(\mathrm{N}=42)$} & \multicolumn{2}{|c|}{ Female $(N=54)$} & \multirow{2}{*}{$t$-value } & \multirow{2}{*}{$p$-value } \\
\hline & Mean & SD & Mean & SD & & \\
\hline \multicolumn{7}{|l|}{ Skeletal } \\
\hline Facial Angle & 85.14 & 3.79 & 84.63 & 4.69 & 0.577 & 0.565 \\
\hline Angle of Convexity & 8.28 & 8.71 & 5.83 & 6.97 & 1.532 & 0.129 \\
\hline A-B Plane Angle & -9.91 & 4.56 & -7.85 & 3.55 & -2.494 & $0.014^{*}$ \\
\hline MP Angle (GoMe-FH) & 23.14 & 7.77 & 26.35 & 7.71 & -2.015 & $0.047^{*}$ \\
\hline Y-axis & 61.15 & 4.39 & 61.54 & 5.81 & -0.363 & 0.717 \\
\hline SNA Angle & 82.30 & 4.46 & 80.38 & 4.01 & 2.214 & $0.029 *$ \\
\hline SNB Angle & 77.04 & 4.63 & 76.11 & 3.42 & 1.138 & 0.258 \\
\hline ANB Angle & 5.35 & 3.35 & 4.27 & 2.54 & 1.793 & 0.076 \\
\hline MP Angle (GoGn-SN) & 27.11 & 8.69 & 30.70 & 7.52 & -2.163 & $0.033^{*}$ \\
\hline Occlusal Plane Angle & 16.59 & 7.50 & 16.27 & 4.88 & 0.250 & 0.803 \\
\hline \multicolumn{7}{|l|}{ Dental } \\
\hline Cant of Occlusal Plane & 9.80 & 5.42 & 8.96 & 5.90 & 0.721 & 0.472 \\
\hline Inter-incisal Angle & 112.88 & 11.19 & 112.48 & 10.14 & 0.183 & 0.855 \\
\hline L1 to Occlusal Plane Angle & 66.42 & 8.04 & 65.27 & 7.55 & 0.720 & 0.474 \\
\hline L1 to Mandibular Plane Angle & 99.50 & 9.31 & 96.83 & 8.57 & 1.456 & 0.149 \\
\hline U1-A Pg Linear (mm) & 11.64 & 2.42 & 11.20 & 3.04 & 0.765 & 0.446 \\
\hline U1-NA Angle & 34.88 & 10.81 & 36.46 & 9.34 & -0.768 & 0.444 \\
\hline U1-NA Linear (mm) & 9.30 & 3.65 & 9.44 & 3.55 & -0.182 & 0.856 \\
\hline L1-NB Angle & 26.97 & 8.12 & 27.05 & 7.58 & -0.049 & 0.961 \\
\hline L1-NB Linear (mm) & 7.23 & 2.86 & 6.85 & 2.70 & 0.677 & 0.500 \\
\hline \multicolumn{7}{|l|}{ Soft tissue } \\
\hline NI-Sn-Pgl & 23.28 & 5.99 & 19.61 & 6.09 & 2.953 & $0.004^{*}$ \\
\hline N1-Pr-Pgl & 51.15 & 5.49 & 48.07 & 5.07 & 2.844 & $0.005^{*}$ \\
\hline Z Angle & 64.90 & 6.97 & 67.14 & 6.92 & -1.570 & 0.120 \\
\hline
\end{tabular}

* Statistically significant at $p \leq 0.05$

The Mandibular Plane Angles; (GoMe-FH) and GoGn-SN were $6.78^{\circ}$ and $6.74^{\circ}$ larger respectively in Chinese. The GoGn-SN mean value was $35.88^{\circ} \pm 6.65$ in Chinese which is nearly same as another study ${ }^{18}$ with $36.7^{\circ} \pm 6.4$ value. The Chinese sample showed lower mean value of facial angle, suggesting more of a retrusive chin. The mean value of $Y$-axis growth and Cant of occlusal plane were higher in Chinese, suggesting downward and rearward chin position. The present study suggests Class II facial pattern in both samples but more prominent in Chinese. Both groups showed greater occlusal plane angle, suggesting vertically growing face and skeletal open bite; in Chinese occlusal plane angle was $6.45^{\circ}$ more, suggesting of long face.

The total soft tissue facial convexity was $5.11^{\circ}$ greater and Z angle was larger in Nepalese sample; suggest more prominent nose and larger chin respectively. Angle of convexity was positive in both samples but lesser in Nepalese sample, suggesting less prominence of maxillary denture base in Nepalese.
The maxillary incisor to Nasion-Point A plane (U1 to NA) angular and linear measurements were greater in Nepalese by $9.22^{\circ}$ and $2.65 \mathrm{~mm}$ respectively, which suggest more axial inclination and forward placement of upper incisor teeth in Nepalese. Contrarily, Mandibular incisor to NasionPoint B plane (L1 to NB) angular and linear measurements were greater in Chinese by $3.74^{\circ}$ and $2.44 \mathrm{~mm}$ respectively, suggesting more axial inclination and forward placement of lower incisor teeth in Chinese. In the present study, mean value of $\mathrm{L} 1$ to mandibular plane angle was $96.82^{\circ} \pm 7.42$ in Chinese, which was nearly same (96.6 \pm 7.0 degree) as in a similar study. ${ }^{18}$

Gender variation exerts little or no effect on skeletal and dental components of Class II malocclusion; 9 this statement has been supported by the present study. Nepalese male subjects showed larger SNA angle and larger negative value in A-B plane angle suggesting of more protrusive maxilla and more retropositioned mandible. The mean values of $\mathrm{GoMe-FH}$, 
GoGn-SN and non significant Z-angle were higher in Nepalese females, suggest longer and less convex facial profile. The angle of soft tissue facial convexity and total soft tissue facial convexity were higher in Nepalese males; suggesting that females have relatively straighter facial profile.

\section{CONCLUSION}

Both Nepalese and Chinese samples showed Class II skeletal pattern, longer anterior face with well positioned maxilla. Nepalese subjects showed protruded maxillary incisors, more prominent nose and chin. Chinese subjects showed more retrusive mandible, skeletal open bite, protruded mandibular incisors, and increased overjet. Nepalese male samples showed more prominent maxilla, retruded mandible and prominent nose than females.
Nepalese samples have distinct cephalometric features, which should be used as a reference in the orthodontic treatment of Nepalese patients. However, this study cannot represent the skeletal norms as a whole; further studies with larger sample would give the overall scenario.

\section{ACKNOWLEDGEMENT}

We express sincere gratitude to Prof Liu Qi gui, statistician at DMU, China for guidance in statistical analysis.

\section{REFERENCES}

1. Drelich RC. A cephalometric study of untreated Class II, division I malocclusion. Angle Orthod 1948; 18:70-5.

2. McNamara Jr JA. Components of Class II malocclusion in children 8-10 years of age. Angle Orthod 1981; 51 (3):177-202

3. Bishara SE, Jakobsen JR, Vorhies B, Bayati P. Changes in dentofacial structures in untreated Class II division 1 and normal subjects: A longitudinal study. Angle Orthod 1997; 67:55-66.

4. Carter NE. Dentofacial changes in untreated Class II division 1 subjects. Br J Orthod 1987; 14(4):225-34

5. Antanas Sidlauskas, Vilma Svalkauskiene, Mantas Sidlauskas. Assessment of skeletal and dental pattern of Class II division 1 malocclusion with Rrelevance to clinical practice. Stomatologija, Baltic Dent Maxillofa J 2006; 8(1):3-8.

6. Henry RG. A classification of Class II division 1 malocclusion. Angle Orthod 1957; 27:83-92.

7. Phelan T, Buschang PH, Behrents RG, Wintergerst AM, Ceen RF, Hernandez A. Variation in Class II malocclusion: comparison of Mexican mestizos and American whites. Am J Orthod Dentofac Orthop 2004; 125(4):418-25.

8. Ishii N, Deguchi T, Hunt NP. Craniofacial morphology of Japanese girls with Class II division 1 malocclusion. J Orthod 2001; 28:21 1-215.

9. Rothstein T, Yoon-Tarlie C. Dental and facial skeletal characteristics and growth of males and females with Class II, division 1 malocclusion between the ages of 10 and 14 (revisited)-part I: Characteristics of size, form, and position. Am J Orthod Dentofac Orthop 2000; $117(3): 320-32$.

10. Moyers RE, Riolo ML, Guire KE, Wainright RL, Bookstein FL. Differential diagnosis of Class II malocclusions. Part 1. Facial types associated with Class II malocclusions. Am J Orthod 1980; 178(5):477- 94.

11. Tukasan PC, Magnani MBBA, Nover DF, Nover PRA, Pereira Neto JS, Garbui IU. Craniofacial analysis of the Tweed Foundation in Angle Class II, division 1 malocclusion, Braz Oral Res 2005;19(1):69-75.

12. Craig CE. The skeletal patterns characteristic of Class I and Class II, division I malocclusions, in normalateralis. Angle Orthod 1951; $21: 44-56$.

13. Blair ES. A cephalometric roentgen graphic appraisal of the skeletal morphology of Class I, Class II, division I and Class II, division 2 (Angle) malocclusion. Angle Orthod 1954; 24:106-19.

14. Harris J E, Kowalski C J, Walker G F. Discrimination between normal and Class II individuals using Steiner's analysis. Angle Orthod 1972 42:212-20.

15. Feldmann I, Lundstrom F, Peck S. Occlusal changes from adolescence to adulthood in untreated patients with Class II division 1 deep bite malocclusion. Angle Orthod 1999; 69(1):33-8.

16. Riedel RA. The relation of maxillary structures to cranium in malocclusion and in normal occlusion. Angle Orthod 1952; 22(3):142- 5.

17. Freitas MR, Santos MAC, Freitas KMS, Janson G, Freitas DS, Henriques JFC. Cephalometric characterization of skeletal Class II division 1 malocclusion in white Brazilian subjects. J Appl Oral Sci 2005; 13(2):198-203.

18. J.W.P. Lau and U. Hägg. Cephalometric morphology of Chinese with Class II Division 1 malocclusion. Br Dent J 1999; 186(4):188-190.

19. Bishara SE. Mandibular changes in persons with untreated and treated Class II division 1 malocclusion. Am J Orthod Dentofac Orthop $1998 ; 113(6): 661-73$.

20. Bishara SE, Cummins DM, Jakobsen JR. The morphologic basis for the extraction decision in Class II division 1 malocclusions: A comparative study. Am J Orthod Dentofac Orthop 1995; 107(2):129-35.

21. Olga-Elpis G. Kolokitha, Sossani Sidiropoulou-Chatzigianni, Smaragda Kavvadia-Tsatala, Nikolaos Topouzelis. Cephalometric study of the position and the size of the mandible in 10-12 years old children with Class II division 1 malocclusion. Hell Orthod Rev 2007; 10(1):41-52.

22. Adams CP, Kerr WJ. Overbite and face height in 44 male subjects with Class I, Class II/1, Class II/2 occlusion. Eur J Orthod 1981; 3:125-9. 